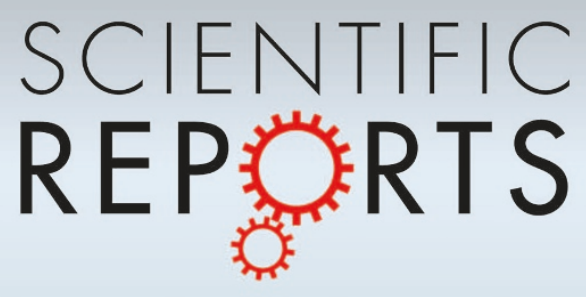

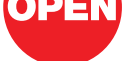

SUBJECT AREAS:

CLIMATE CHANGE

COMPUTATIONAL BIOLOGY

MATHEMATICS AND

COMPUTING

MODELLING

Received

12 July 2011

Accepted

29 July 2011

Published

18 August 2011

Correspondence and requests for materials should be addressed to M.A.S. (mikhail. semenov@bbsrc.ac.

uk)

\title{
Modelling predicts that heat stress, not drought, will increase vulnerability of wheat in Europe
}

\author{
Mikhail A. Semenov' \& Peter R. Shewry ${ }^{2}$ \\ ${ }^{1}$ Centre for Mathematical and Computational Biology, Rothamsted Research, Harpenden, Herts, AL5 2JQ, UK, ${ }^{2}$ Centre for Crop \\ Genetic Improvement, Rothamsted Research, Harpenden, Herts, AL5 2JQ, UK.
}

\begin{abstract}
New crop cultivars will be required for a changing climate characterised by increased summer drought and heat stress in Europe. However, the uncertainty in climate predictions poses a challenge to crop scientists and breeders who have limited time and resources and must select the most appropriate traits for improvement. Modelling is a powerful tool to quantify future threats to crops and hence identify targets for improvement. We have used a wheat simulation model combined with local-scale climate scenarios to predict impacts of heat stress and drought on winter wheat in Europe. Despite the lower summer precipitation projected for 2050s across Europe, relative yield losses from drought is predicted to be smaller in the future, because wheat will mature earlier avoiding severe drought. By contrast, the risk of heat stress around flowering will increase, potentially resulting in substantial yield losses for heat sensitive cultivars commonly grown in northern Europe.
\end{abstract}

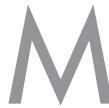
ost global climate models (GCMs) from the Coupled Model Intercomparison Project phase 3 (CMIP3) multi-model dataset predict a decrease of precipitation during summer in Europe (Fig. SI.1) $)^{1,2}$. Availability of water for plant growth is a key factor determining plant distribution in natural ecosystems and is the most important limiting factor in agricultural systems ${ }^{3}$. GCMs also predict a substantial increase in temperature and in the frequency and magnitude of extreme weather events in Europe $e^{4-6}$. It has been shown that heat waves in the UK are predicted to increase in frequency (by an order of magnitude), length and severity (peak temperature) by the end of the century ${ }^{7}$. Even isolated incidents of extreme high temperature around a sensitive stage of crop development, such as flowering, could reduce grain yield considerably, while a continuous period of extreme high temperature could result in almost total yield loss ${ }^{8}$. A modelling study for the main wheat growing regions of Australia demonstrated that variations in average growing-season temperatures of $2{ }^{\circ} \mathrm{C}$ can cause reductions in grain production of up to $50 \%$, most of which can be attributed to increased leaf senescence as a result of high temperatures'. Another study in the USA demonstrated that nonlinear temperature effects on grain yields, which show a steep yield decline after temperature exceeds crop-specific thresholds, could lead to severe damages to U.S. corn and soybeans yields under climate change ${ }^{10}$.

The objective of this study was to quantify the impacts of drought and heat stress on winter wheat under climate change and to determine which of these factors is likely to increase vulnerability of wheat in Europe. The importance of increased temperature relative to changes in precipitation on crop yields was studied before ${ }^{11}$. However, these authors investigated the effect of changes in mean climate using a regression model of the crop yield sensitivity, which is not appropriate to study the impact of extreme events. In our study, we used a wheat simulation model combined with local-scale climate scenarios based on the CMIP3 multi-model ensemble to predict impacts of climate change on winter wheat in Europe. We were able to quantify changes in extreme weather events and their impacts on wheat, including probability of heat stress around flowering and yield losses resulting from drought. By using climate projections from the CMIP3 multi-model ensemble, we were able to quantify uncertainty in our predictions and increase robustness of our conclusions, which makes this study different from the results reported previously for the UK, where a single climate model, HadRM3, was used ${ }^{12}$.

The wheat yield could be limited by the grain number and the grain size, which are established to a large extent at the period around anthesis (flowering), a stage in development known to be sensitive to high temperature stress $^{8}$. If the crop is unstressed, it establishes the grain number and its potential size at sufficiently large values to accommodate biomass produced during grain filling. In this case, the yield is effectively source-limited ${ }^{13}$. The grain number and the grain size can be substantially reduced if a cultivar, sensitive to heat stress, is exposed to a 
short period of high temperature around flowering, limiting the capacity of grains to store newly produced biomass. In this case, grain growth becomes a sink-limited process. In an experiment on the combine effects of $\mathrm{CO}_{2}$ and temperature on the grain yield Mitchell et al. (1993) ${ }^{14}$ observed that a temperature of $27^{\circ} \mathrm{C}$ or higher applied mid-way through anthesis could result in a high number of sterile grains and considerable yield losses. Wheeler et al (1996) ${ }^{15}$ used a temperature gradient tunnel system to demonstrate that a temperature of $30^{\circ} \mathrm{C}$ or higher prior to anthesis significantly reduced the grain number and, subsequently, yield of $c v$. Hereward. In experiments in Australia ${ }^{16}$, plants were transferred into controlled rooms with high temperatures 7 days after the first anthers appeared, showing that a temperature of $27^{\circ} \mathrm{C}$ and above could substantially reduce the maximum grain size of several Australian wheat cultivars, resulting in substantial yield losses.

\section{Results}

We used a wheat simulation model, Sirius ${ }^{17}$, combined with climate scenarios to predict impacts of climate change on winter wheat across Europe. Local-scale climate scenarios were generated by the LARS-WG weather generator ${ }^{18}$ and were based on the projections of

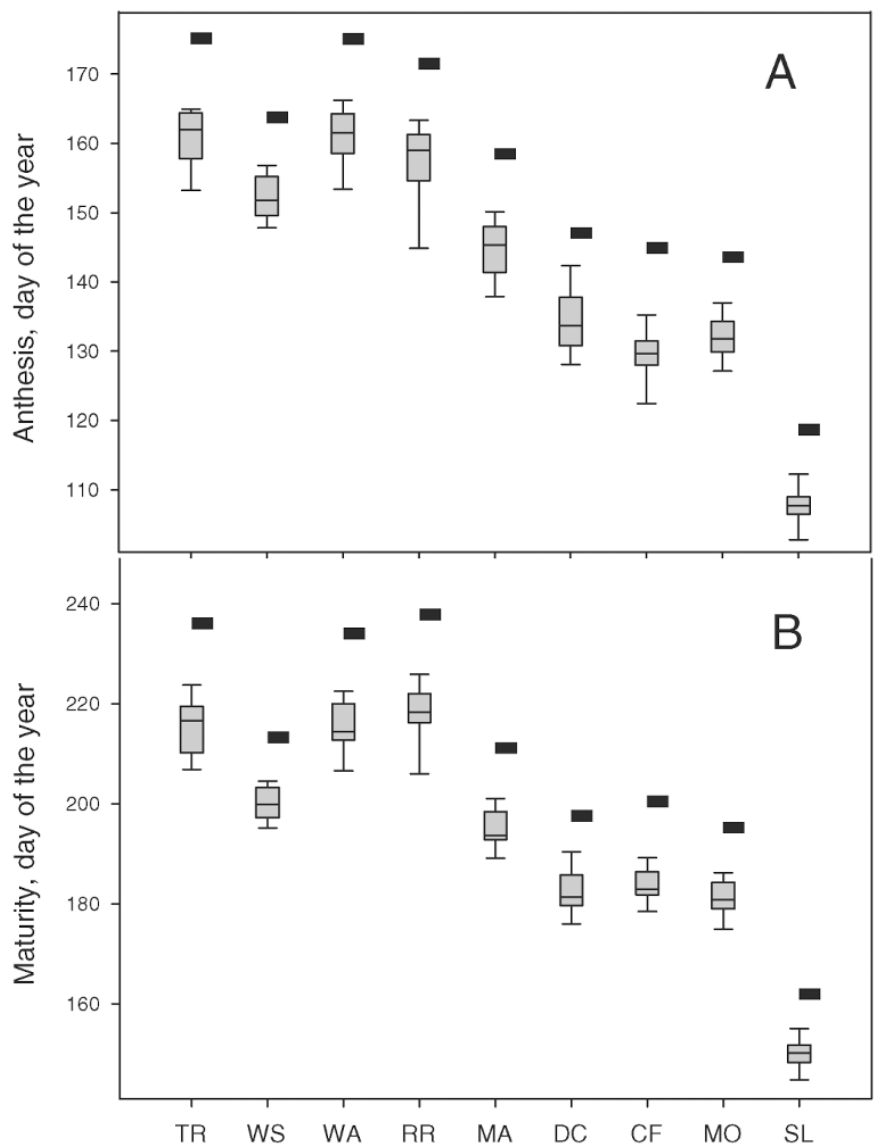

Figure $1 \mid$ (A) Anthesis, and (B) maturity. Mean simulated day of anthesis and maturity for the baseline (black rectangles) and for the 2055(A1B) scenario (box plots) at nine European sites: TR (Tylstrup, Denmark), WS (Warsaw, Poland), WG (Wageningen, the Netherlands), RR (Rothamsted, UK), MA (Mannheim, Germany), DC (Debrecen, Hungary), CF (Clermont-Ferrand, France), MO (Montagnano, Italy) and SL (Seville, Spain) (see Table SI.1 for details). Box plots are constructed from 15 predictions of mean day of anthesis (and maturity) for climate scenarios (each consists of 300 yrs of daily weather) based on 15 individual GCMs from the CMIP ensemble. Box boundaries indicate the 25 and 75-percentiles, the line within the box marks the median, whiskers below and above the box indicate the 10 and 90 -percentiles. fifteen global climate models from the CMIP3 multi-model ensemble. We estimated the probability of the maximum daily temperature exceeding a temperature threshold of $27^{\circ} \mathrm{C}$ and $30^{\circ} \mathrm{C}$ at two stages, at anthesis and at 5 days after anthesis. For heat sensitive cultivars, high temperature at anthesis can reduce the grain number and heat stress 5 days after anthesis can reduce the grain size. The reduction in the grain number and the grain size can subsequently reduce the grain yield. To assess the effect of severe drought on grain yield, we computed 95-percentile of a drought stress index (DSI95). Drought stress index, DSI, is defined as a proportion of the yield lost due to water stress: $\mathrm{DSI}=1-\mathrm{Y}_{\mathrm{WL}} / \mathrm{Y}_{\mathrm{P}}$, where $\mathrm{Y}_{\mathrm{WL}}$ and $\mathrm{Y}_{\mathrm{P}}$ are waterlimited and potential grain yields. DSI95 is a yield loss due to water stress, which are expected to occur once every 20 years on average.

The simulation was run for nine European sites (Table SI.1 and Fig SI.1). For each site and each GCM from the CMIP3 ensemble, we generated using the LARS-WG weather generator 300 years of daily weather representing the baseline scenario corresponding to 19601990, and the future climate scenario corresponding to 2046-2065 for the A1B emission scenario, denoted as 2055(A1B). For each site we selected a typical winter wheat cultivar, which was calibrated previously using field experiments (Table SI.1) ${ }^{19-22}$. To make a comparison between sites, we used one soil for all sites, medium loamy drift with siliceous stones, with relatively low available water capacity (AWC) of $131 \mathrm{~mm}$. Future values of probability of heat stress around flowering and DSI95 were calculated for each of fifteen GCMs individually and then presented as box plots to indicate the uncertainty in predictions.

Fig. 1 shows simulated anthesis and maturity dates (day of the year). Increase in temperature accelerates wheat development, bringing forward anthesis on average by 13.2 days and maturity by 17.5 days. Fig. 2 shows simulated yields for the baseline and 2055(A1B) scenarios. Rising $\mathrm{CO}_{2}$ concentration ( $\left[\mathrm{CO}_{2}\right]$ ) will increase the productivity of $\mathrm{C}_{3}$ crops, including wheat. As a result, the simulated yield for the 2055(A1B) scenario was on average 14.9\% higher than for the baseline across sites. Although winter wheat cultivars from northern Europe are known to be sensitive to heat stress around anthesis ${ }^{14,15}$, the lack of sufficient experimental data did not allow us to calibrate cultivar parameters for heat sensitivity. Therefore, we assume that all wheat cultivars in simulations were heat tolerant and yields were not affected directly by the heat stress around anthesis.

Accumulation of biomass is proportional to the radiation intercepted by the plant. Earlier maturity for the 2055(A1B) climate

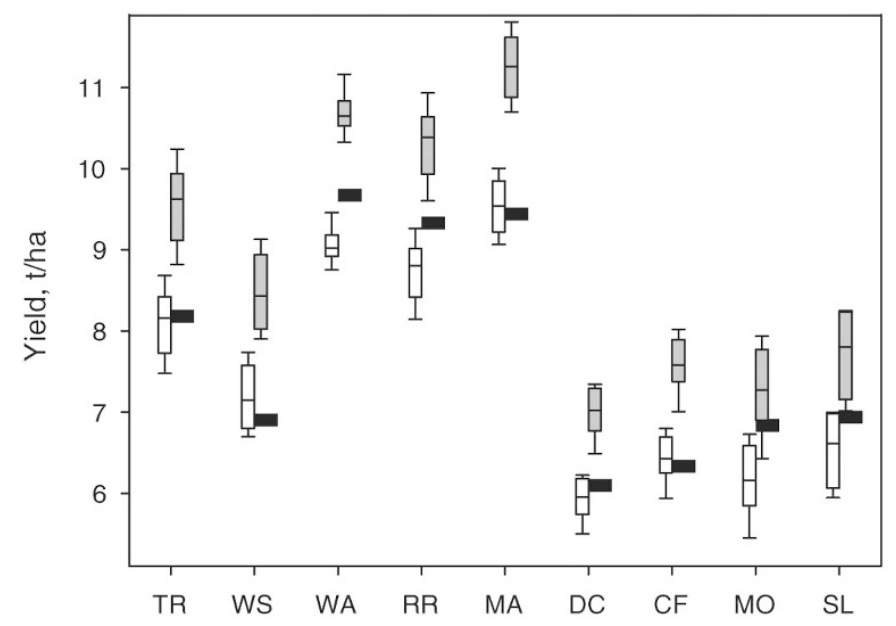

Figure $2 \mid$ Grain yield. Mean simulated grain yield for the baseline (black rectangles) and for the 2055(A1B) climate scenario with no change in $\left[\mathrm{CO}_{2}\right]$ of $338 \mathrm{ppm}$ (considering effect of change in climate only, open box plots) and increased $\left[\mathrm{CO}_{2}\right]$ of $541 \mathrm{ppm}$ (gray box plots) corresponding to the A1B emission scenario. All wheat cultivars were assumed to be tolerant to heat stress around anthesis. 


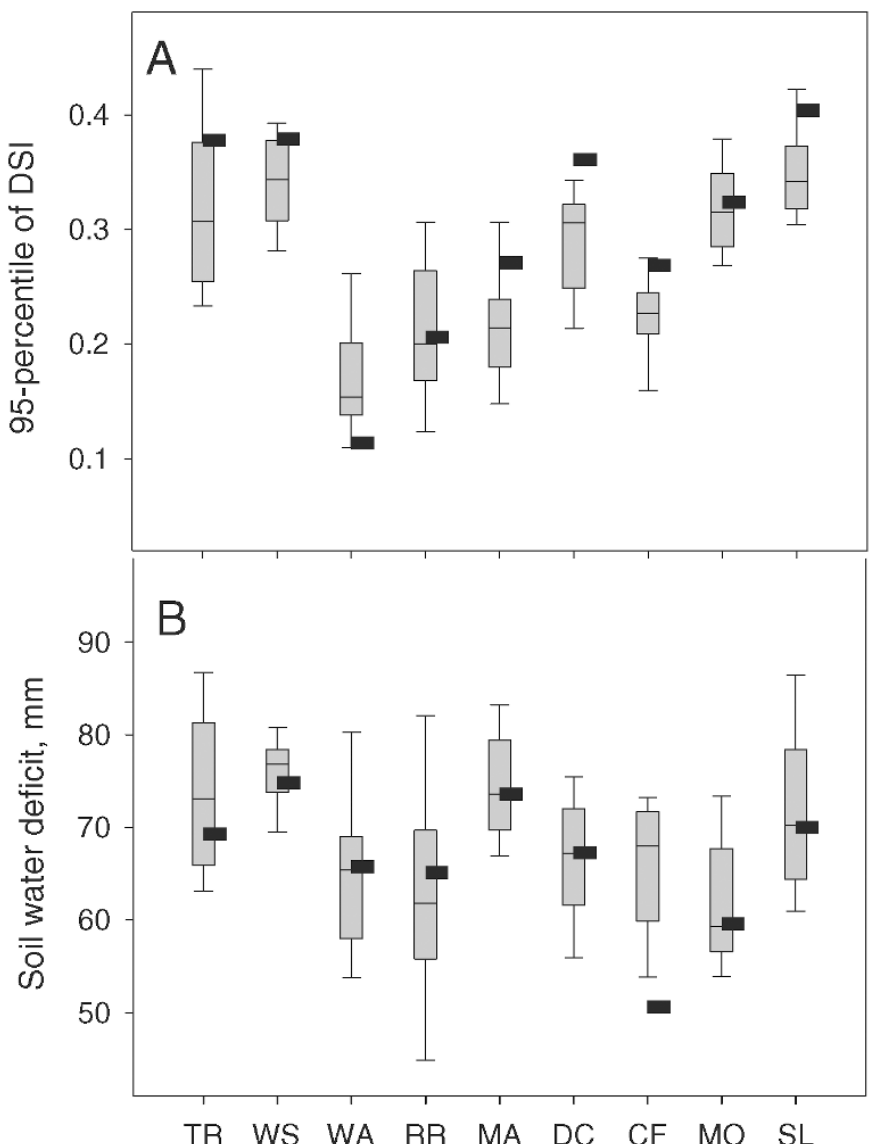

Figure $3 \mid$ (A) 95-perccentiles of DSI, and (B) soil water deficit at anthesis. For the baseline (black rectangles) and for the 2055(A1B) climate scenarios (box plots). scenario should, in principle, reduce the potential yield, because the amount of radiation, which plant can intercept, is lower. However, in water-limited environments, the situation is more complex. There is a trade-off in maximizing the yield between increasing duration of grain filling and avoiding severe water stress. To illustrate the effect of changes in climate only on grain yield, we run simulations for the 2055(A1B) scenario with [CO2] of $338 \mathrm{ppm}$, the same as we used for the baseline scenario. On average, the yields for the 2055(A1B) scenario decreased by about $2.6 \%$ (Fig. 2). For the sites where water stress was relatively low, e.g. RR or WA, reductions in yields were larger, $5.6 \%$ and $6.7 \%$. However, at some sites, e.g. WS and CF, wheat yield increased, because earlier maturity reduced water stress during grain filling.

Fig. 3A shows box plots of DSI95. For all sites except WA, the medians of predicted DSI95 for fifteen GCMs for the 2050(A1B) scenario were lower that the values of DSI95 for the baseline scenario. This means that despite a decrease in precipitation during summer in northern Europe and during the whole growing season in southern Europe (Fig. SI.1), relative yield losses from drought were predicted to be smaller in the future than at present even for currently grown wheat cultivars. Maturity dates are predicted to be 2-3 weeks earlier for the 2055(A1B) scenario compared with 1960-1990 (Fig. 1B). Because soil water deficit (SWD) increases towards the end of crop growth, wheat will avoid the most severe drought stress by maturing early. It is interesting to note (Fig. 3B) that SWD at anthesis does not vary greatly between southern and northern sites and the median of SWD at anthesis is predicted to stay at about the same level in the future with one exception, CF, where it increased from 50 to $67 \mathrm{~mm}$.

Medians of monthly mean maximum temperatures for the 2050(A1B) scenario are predicted to increase between 1.5 and $3.5^{\circ} \mathrm{C}$ depending on the month and the site (Fig. SI.1). Fig. 4 shows the probability of two events: first, when the maximum daily temperature within 3 days of anthesis exceeded a temperature threshold of $27^{\circ} \mathrm{C}$ or $30^{\circ} \mathrm{C}$ (Fig. $4 \mathrm{~A}$ and $4 \mathrm{C}$ ), and second, when the maximum temperature exceeded thresholds both within 3 days of anthesis and

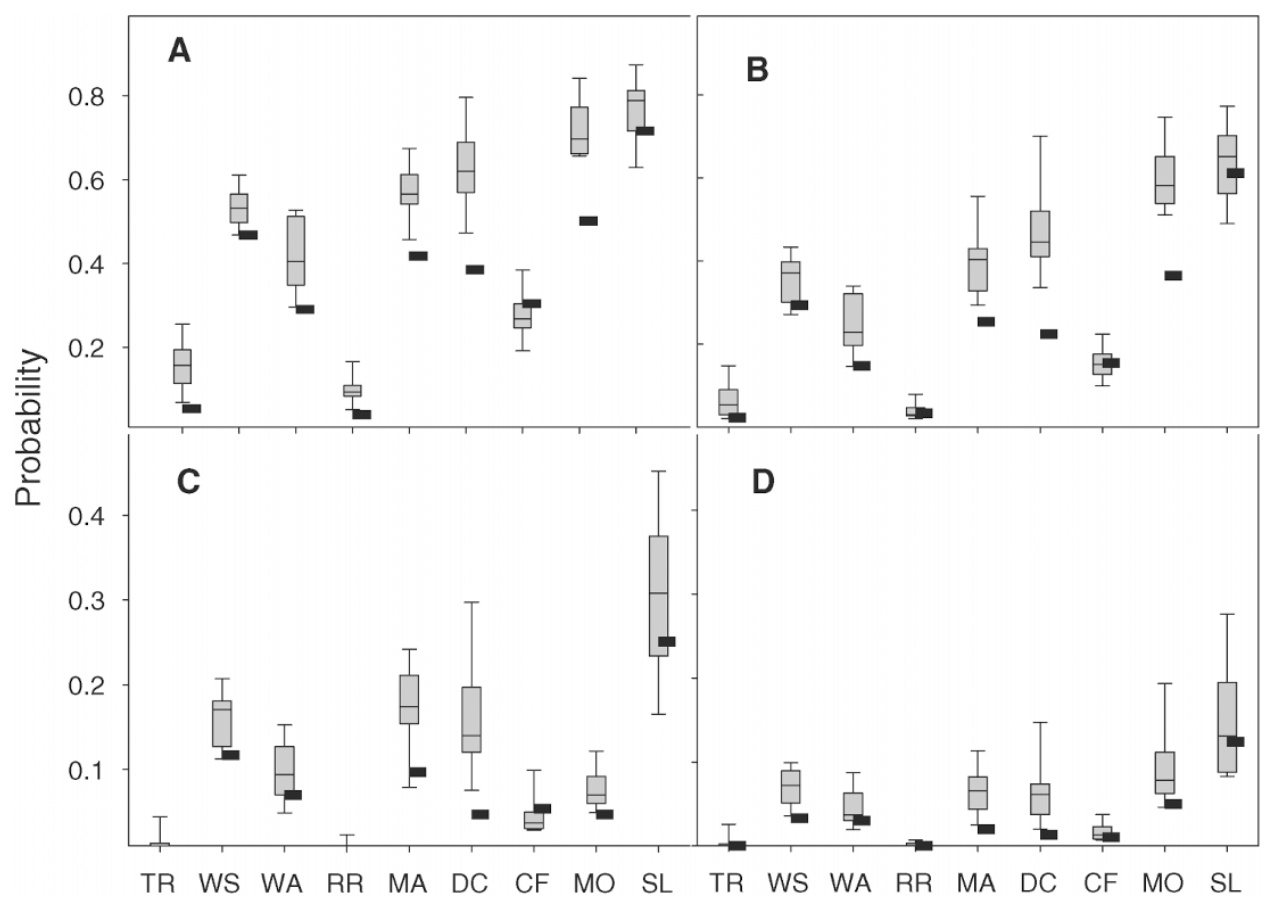

Figure $4 \mid$ Probability of maximum temperature exceeding temperature thresholds. Thresholds of $27^{\circ} \mathrm{C}(\mathrm{A}, \mathrm{B})$ or $30^{\circ} \mathrm{C}(\mathrm{C}, \mathrm{D})$ within 3 days of anthesis $(\mathrm{A}, \mathrm{C})$ or consecutively with 3 days of anthesis and within 3 days of five days after anthesis (B,D) for the baseline (black rectangles) and for the 2055(A1B) climate scenarios (box plots). Sirius was used to calculate anthesis dates for each individual year of baseline and 2055(A1B) climate scenarios for 15 GCMs from the CMIP3 ensemble. 
within 3 days of five days after anthesis (Fig. $4 \mathrm{~B}$ and 4D). Probabilities for both events are predicted to increase for all sites, except CF, with larger relative increases for northern sites. Exceeding a temperature threshold at anthesis will reduce the grain number for heat sensitive cultivars, while exceeding a temperature threshold five days after anthesis will reduce the potential grain size. Each of these events alone can reduce the grain yield for heat sensitive wheat cultivars. If these events happen concurrently the yield losses could be substantial. Although winter wheat cultivars from northern Europe are known to be sensitive to heat stress around anthesis ${ }^{15}$, the lack of sufficient experimental data did not allow us to calibrate parameters for heat sensitivity for individual cultivars and to assess yield losses resulting directly from heat stress around anthesis. More experimental studies to quantify these effects are needed ${ }^{23}$.

\section{Discussion}

Wheat is the most important crop in temperate zones, including Europe, and is the staple food crop for many millions of humans and their livestock. New wheat cultivars will, therefore, be required if climate change is not to result in losses of yield and food shortages. Our results demonstrate that the impacts of changing climate on wheat can be counter-intuitive and that the severity of the impact will depend on cultivar characteristics and on the spatial and temporal patterns of climate change. Drought is the most significant environmental stress in agriculture worldwide and improving yields in water-limited environments is a major goal of plant breeding ${ }^{24}$. Some researchers suggest that the impact of drought will increase with climate change ${ }^{25}$, emphasising the importance of breeding for drought tolerant crops, and this will certainly be true for many crops and environments. However, our analysis demonstrates that drought will not increase vulnerability of wheat in Europe under climate change and relative yield losses from water stress are likely to decrease across Europe. In fact, it showed that a more serious threat for wheat production in Europe may result from an increase in frequency and magnitude of heat stress around flowering with potentially significant yield losses for heat sensitive wheat cultivars commonly grown in northern Europe. Having limited time and resources, crop scientists and breeders must select the most appropriate traits for crop improvement and should, therefore, focus on the development of wheat varieties, which are resistant to high temperature around flowering, rather than on developing varieties tolerant to drought, which may be required for other parts of the world.

\section{Methods}

To construct local-scale daily climate scenarios, we used the CMIP3 multi-model ensemble of climate projections ${ }^{1,26}$. This ensemble was constructed by running several GCMs for a common set of climate experiments to assess the uncertainty in climate predictions resulting from structural differences in climate models. The direct use of climate predictions from the CMIP3 ensemble in conjunction with a crop simulation model is not possible because of the coarse spatial resolution of GCMs resulting in significant errors and large uncertainty in their output at a local scale, particularly for precipitation. The source of errors is related to the fact that many small-scale processes cannot be represented explicitly in GCM, and must be approximated. Various downscaling techniques have been developed to underpin studies on regional and local scale climate impact assessments, including dynamic downscaling ${ }^{27}$, statistical downscaling $^{28,29}$ and weather generators ${ }^{30}$. We used the LARS-WG weather generator to downscale GCM projections from the CMIP3 ensemble to a local scale ${ }^{31}$. LARSWG has been tested across Europe and showed a good performance in simulating diverse European climates ${ }^{18}$. By altering the baseline site parameters using changes in climate predicted by GCM, it is possible to generate synthetic daily weather for the future. The use of WG in climate change studies allows exploration of the effect of changes in mean climate as well as changes in climatic variability and extreme events ${ }^{7}$. The latter could be critically important for analysis of agricultural and biological systems that incorporate non-linear interactions between system components and the surrounding environment ${ }^{32,33}$. Climate projections for each GCM from the CMIP3 ensemble were treated as equally probable predictions of the evolution of the climate system. Only one SRES emission scenario, A1B, and one time period, 2046-2065, were used in the simulations.

The Sirius wheat simulation model was used to calculate crop growth and grain yield ${ }^{17}$. Sirius was calibrated for several modern wheat cultivars and was able to simulate accurately crop growth in a wide range of environments, including Europe,
USA, NZ and Australia, and under climate change $\mathrm{e}^{20,34}$. The model requires daily weather data, a soil physical description and management information to calculate biomass accumulation from intercepted photosynthetically active radiation day by day. Grain growth is calculated using simple partitioning rules. Phenological development is linked to the mainstem leaf appearance rate (determined by temperature) and the final leaf number, determined by responses to daylength and vernalisation $^{35}$

In Sirius, radiation use efficiency (RUE) is proportional to [CO2] with increase of $30 \%$ for doubling in [CO2] compared with the baseline [CO2] of $338 \mathrm{ppm}$. A similar response was used by other wheat simulation models, e.g. CERES ${ }^{19}$ and EPIC $^{36}$. Long et al $(2006)^{37}$ argued that the results from FACE experiments demonstrated lower effect of elevated [CO2] on wheat yield ${ }^{38,39}$. To illustrate uncertainty in response of RUE to elevated $\left[\mathrm{CO}_{2}\right]$, we simulated future yields also for a lower value of $15 \%$ of increase in RUE for doubling in [CO2] (Fig. SI3).

To demonstrate the effect of soil with high AWC on DSI, we run additional simulations for a soil with AWC $=196 \mathrm{~mm}$ (Fig. SI.4). As expected, DSI95 for this soil was much lower than for the soil with $\mathrm{AWC}=131 \mathrm{~mm}$ and showed even larger relative decrease for the 2055(A1B) scenario compare with the baseline (Fig. SI.4A).

Variation in the sowing date could be considered as an adaptation option to a changing climate in order to reduce the effect of heat stress or drought on crop yield. Fig. SI5 demonstrates the effect of variation in the sowing date on DSI, probability of heat stress at anthesis and grain yield at two sites, TR and WS. Sowing dates were varied between 262 and 322. The sowing date of 292 for the 2050(A1B) scenario produced near-optimal performance of wheat, with the high yield, low risk of heat stress and low DSI (Fig. SI5). This date was used as default for the baseline scenario at both sites.

1. Meehl, G. A. et al. The WCRP CMIP3 multi-model dataset: A new era in climate change research. Bull. Amer. Meteorol. Soc. 88 (2007).

2. Solomon, S. et al. Climate Change 2007: The Physical Science Basis. 996 (Cambridge University Press, NY, 2007).

3. Bacon, M. A. Water use efficiency in plant biology. in Biological Science Series 327 (Blackwell Publishing, Oxford, 2004).

4. Weisheimer, A. \& Palmer, T. N. Changing frequency of occurrence of extreme seasonal-mean temperatures under global warming. Geophys. Res. Let. 32, L2072 (2005).

5. Beniston, M. et al. Future extreme events in European climate: an exploration of regional climate model projections. Climatic Change 81, 71-95 (2007).

6. Barnett, D. N., Brown, S. J., Murphy, J. M., Sexton, D. M. H. \& Webb, M. J. Quantifying uncertainty in changes in extreme event frequency in response to doubled CO2 using a large ensemble of GCM simulations Clim. Dynam. 26, 489511 (2006).

7. Semenov, M. A. Development of high-resolution UKCIP02-based climate change scenarios in the UK. Agr. Forest Meteorol. 144, 127-138 (2007).

8. Porter, J. R. \& Semenov, M. A. Crop responses to climatic variation. Philos. T. R. Soc. B 360, 2021-2035 (2005)

9. Asseng, S., Foster, I. \& Turner, N. C. The impact of temperature variability on wheat yields. Glob. Change Biol. 17, 997-1012 (2011).

10. Schlenkera, W. \& Roberts, M. J. Nonlinear temperature effects indicate severe damages to U.S. crop yields under climate change. PNAS 106, 15594-15598 (2009).

11. Lobell, D. B. \& Burke, M. B. Why are agricultural impacts of climate change so uncertain? The importance of temperature relative to precipitation. Environ. Res Let. 3.

12. Semenov, M. A. Impacts of climate change on wheat in England and Wales. J.R.S Interface 6, 343-350 (2009).

13. Sinclair, T. R. \& Jamieson, P. D. Grain number, wheat yield, and bottling beer: An analysis. Field Crops Res. 98, 60-67 (2006).

14. Mitchell, R. A. C., Mitchell, V. J., Driscoll, S. P., Franklin, J. \& Lawlor, D. W. Effects of increased $\mathrm{CO} 2$ concentration and temperature on growth and yield of winterwheat at 2 levels of nitrogen application. Plant Cel Environ. 16, 521-529 (1993).

15. Wheeler, T. R. et al. The duration and rate of grain growth, and harvest index, of wheat (Triticum aestivum L) in response to temperature and CO2. J. Exp.Bot. 47, 623-630 (1996)

16. Tashiro, T. \& Wardlaw, I. F. A comparison of the effect of high-temperature on grain development in wheat and rice. Ann. Bot. 64, 59-65 (1989).

17. Jamieson, P. D., Semenov, M. A., Brooking, I. R. \& Francis, G. S. Sirius: a mechanistic model of wheat response to environmental variation. Eur. J. Agron. 8, 161-179 (1998).

18. Semenov, M. A., Donatelli, M., Stratonovitch, P., Chatzidaki, E. \& Baruth, B. ELPIS: a dataset of local-scale daily climate scenarios for Europe. Clim. Res. 44, 3-15 (2010).

19. Jamieson, P. D. et al. Modelling $\mathrm{CO} 2$ effects on wheat with varying nitrogen supplies. Agr. Ecosyst. Environ. 82, 27-37 (2000).

20. Ewert, F. et al. Effects of elevated CO2 and drought on wheat: testing crop simulation models for different experimental and climatic conditions. Agr. Ecosyst. Environ. 93, 249-266 (2002).

21. Lawless, C., Semenov, M. A. \& Jamieson, P. D. A wheat canopy model linking leaf area and phenology. Eur. J. Agron. 22, 19-32 (2005).

22. Ferrise, R., Triossi, A., Stratonovitch, P., Bindi, M. \& Martre, P. Sowing date and nitrogen fertilisation effects on dry matter and nitrogen dynamics for durum wheat: An experimental and simulation study. Field Crops Res. 117, 245-257 (2010). 
23. Rötter, R. P., Carter, T. R., Olesen, J. E. \& Porter, J. R. Crop-climate models need an overhaul. Nature Climate Change 1, 175-177 (2011).

24. Cattivelli, L. et al. Drought tolerance improvement in crop plants: An integrated view from breeding to genomics. Field Crops Res. 105, 1-14 (2008).

25. Witcombe, J. R., Hollington, P. A., Howarth, C. J., Reader, S. \& Steele, K. A. Breeding for abiotic stresses for sustainable agriculture. Philos. T. R. Soc. B 363, 703-716 (2008).

26. Annan, J. D. \& Hargreaves, J. C. Reliability of the CMIP3 ensemble. Geophys. Res. Let. 37.

27. Rummukainen, M. State-of-the-art with regional climate models. WIREs Climate Change 1, 82-96 (2010).

28. Murphy, J. An evaluation of statistical and dynamical techniques for downscaling local climate. J. Climate 12, 2256-2284 (1999).

29. Fowler, H. J., Blenkinsop, S. \& Tebaldi, C. Linking climate change modelling to impacts studies: recent advances in downscaling techniques for hydrological modelling. Int. J. Climatol. 27, 1547-1578 (2007).

30. Wilks, D. S. \& Wilby, R. L. The weather generation game: a review of stochastic weather models. Prog. Phys. Geog. 23, 329-357 (1999).

31. Semenov, M. A. \& Stratonovitch, P. The use of multi-model ensembles from global climate models for impact assessments of climate change. Clim. Res. 41, 1-14 (2010).

32. Semenov, M. A. \& Porter, J. R. Climatic variability and the modeling of crop yields. Agr. Forest Meteorol. 73, 265-283 (1995).

33. Mearns, L. O., Rosenzweig, C. \& Goldberg, R. Mean and variance change in climate scenarios: Methods, agricultural applications, and measures of uncertainty. Climatic Change 35, 367-396 (1997).

34. Martre, P. et al. Modelling protein content and composition in relation to crop nitrogen dynamics for wheat. Eu. J. Agron. 25, 138-154 (2006).

35. Jamieson, P. D. et al. Reconciling alternative models of phenological development in winter wheat. Field Crops Res. 103, 36-41 (2007).

36. Tubiello, F. N., Donatelli, M., Rosenzweig, C. \& Stockle, C. O. Effects of climate change and elevated $\mathrm{CO} 2$ on cropping systems: model predictions at two Italian locations. Eur. J. Agron. 13, 179-189 (2000)

37. Long, S. P., Ainsworth, E. A., Leakey, A. D. B., Nosberger, J. \& Ort, D. R. Food for thought: Lower-than-expected crop yield stimulation with rising $\mathrm{CO} 2$ concentrations. Science 312, 1918-1921 (2006).
38. Ainsworth, E. A., Leakey, A. D. B., Ort, D. R. \& Long, S. P. FACE-ing the facts: inconsistencies and interdependence among field, chamber and modeling studies of elevated [CO2] impacts on crop yield and food supply. New Phytol. 179, 5-9 (2008).

39. Tubiello, F. N. et al. Crop response to elevated CO2 and world food supply - A comment on "Food for Thought..." by Long et al., Science 312 : 1918-1921, 2006. Eur. J. Agron. 26, 215-223 (2007).

\section{Acknowledgements}

We acknowledge the modelling groups, the Program for Climate Model Diagnosis and Intercomparison (PCMDI) and the WCRP's Working Group on Coupled Modelling (WGCM) for their roles in making available the WCRP CMIP3 multi-model dataset. Support of this dataset is provided by the Office of Science, U.S. Department of Energy. Rothamsted Research receives grant aided support from the Biotechnology and Biological Sciences Research Council of the United Kingdom.

\section{Authors contributions}

MAS was responsible for model development, simulations and analysis. Both authors contributed to writing the manuscript.

\section{Additional information}

Supplementary Information accompanies this paper at http://www.nature.com/ scientificreports

Competing financial interests: The authors declare no competing financial interests.

License: This work is licensed under a Creative Commons

Attribution-NonCommercial-NoDerivative Works 3.0 Unported License. To view a copy of this license, visit http://creativecommons.org/licenses/by-nc-nd/3.0/

How to cite this article: Semenov, M.A. \& Shewry, P.R. Modelling predicts that heat stress, not drought, will increase vulnerability of wheat in Europe. Sci. Rep. 1, 66; DOI:10.1038/ srep00066 (2011). 